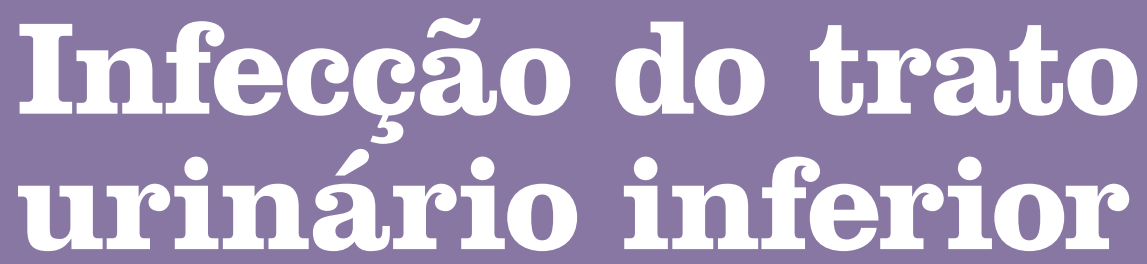
em cães

\title{
Revisão de literatura
}

\section{Lower urinary tract infection in dogs}

\author{
Literature review
}

\section{Resumo}

O presente trabalho tem como objetivo revisar a infecção do trato urinário inferior (ITUI) de cães. Cistite é o nome que se dá às doenças inflamatórias e/ou infecciosas da vesícula urinária ou bexiga, caracterizando-se clinicamente por estrangúria, bem como pela presença de células inflamatórias, sangue e bactérias na urina. Um animal com ITUI pode ficar ou permanecer assintomático, especialmente se a infecção for secundária a aumento da concentração de glicocorticoides. Eschericchia coli, Proteus spp, Pseudomonas aeruginosa e Enterobacter spp são exemplos de patógenos urinários que podem estar presentes na ITUI. Portanto, quando antibióticos são selecionados com base em antibiograma, é mais provável que ocorra uma boa resposta clínica. Alguns autores relatam que a bactéria com maior frequência de isolamento em casos de cistite infecciosa em cães é a Eschericchia coli. É necessária a realização rotineira de testes de suscetibilidade microbiana, especialmente em casos de infecção do trato urinário inferior.

\section{Summary}

The present study aims to review the lower urinary tract infection (UTI) of dogs. Cystitis is the name given to inflammatory diseases and/or infection of the urinary bladder or bladder is characterized clinically by strangury as well as the presence of inflammatory cells, blood and bacteria in the urine. An UTI animal can stay or remain asymptomatic, especially if the infection is secondary to increased concentrations of glucocorticoids. Eschericchia coli, Proteus spp, Pseudomonas aeruginosa and Enterobacter spp are examples of urinary pathogens that may be present in UTI. Therefore, when antibiotics are selected on the basis of antibiogram, it is more likely to experience a good clinical response. Some authors suggest that the bacterium most frequently isolated in cases of cystitis in dogs is contagious Eschericchia coli. It is necessary to perform routine testing microbial susceptibility, especially in cases of lower urinary tract infection. 
Avenida Gustavo Adolfo, 2831

03361-010 - São Paulo, SP

こ +5511 6918-0817 ‘ +55118261-5314

凶nassaribeiro@hotmail.com

\section{Palavras-chave}

Infecção do trato urinário inferior. Cistite. Cães.

\section{Keywords}

Lower urinary tract infection. Cystitis. Dogs.

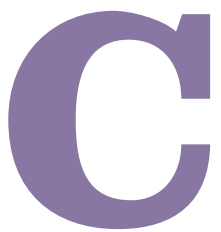

istite é o nome que se dá às doenças inflamatórias e/ou infecciosas da vesícula urinária ou bexiga, caracterizando-se clinicamente por estrangúria, bem como pela presença de células inflamatórias, sangue e bactérias na urina (Blood, 1991, Lulich et al., 2004).

Visto ser improvável que as infecções bacterianas fiquem confinadas à vesícula urinária sem que a uretra seja afetada, é mais apropriado utilizar a terminologia de "infecção do trato urinário inferior" (ITUI) ou "uretrocistite" (Lulich, 1997).

Outros sinais clínicos frequentemente associados à ITUI incluem urina com odor ou aparência anormais (hematúria e turbidez), disúria, polaciúria ou, menos frequentemente, incontinência urinária. Os sinais sistêmicos são raros quando a infecção se limita à vesícula urinária. É importante salientar que um animal com ITUI pode ficar ou permanecer assintomático, especialmente se a infecção for secundária a aumento da concentração de glicocorticoides (por exemplo, hiperadrenocorticismo e agentes iatrogenicamente administrados) ou o diabetes mellitus (Cowan, 1998), cateterização e uretrostomia recente (Lulich, 1997, Nelson e Couto, 2001, Lulich et al., 2004).

Embora a patogênese das infecções do trato urinário seja um tanto obscura, sabe-se que ela depende do equilíbrio entre agentes infecciosos uropáticos e a resistência do hospedeiro. Apesar do fato de que o uso de agentes antimicrobianos, objetivando a eliminação de 


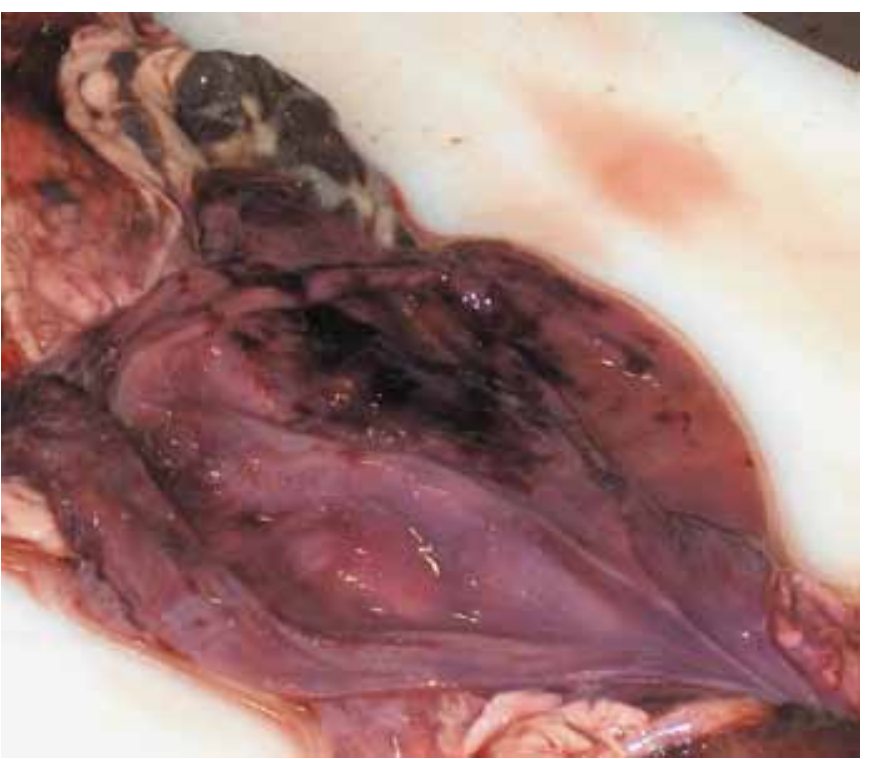

Figura 1: Cistite em Vesícula urinária - J.L. Guerra - UAM, 2007

uropatógenos, permaneça sendo a pedra angular da terapia, a situação dos mecanismos de defesa do hospedeiro constitui importante fator na patogênese das infecções do trato urinário. Em outras palavras, anormalidades nas defesas do hospedeiro representam importantes causas predisponentes das infecções do trato urinário, subjacente à causa tradicionalmente aceita dos agentes microbianos (Lulich, 1997, Lulich et al., 2004).

Alguns fatores predisponentes incluem inflamação, cateterização, glicocorticoides, retenção urinária, cálculos e neoplasia, e podem anular as defesas da mucosa vesical. A cateterização vesical pode causar irritação mecânica ou o cateter pode servir como acesso para as bactérias entrarem na vesícula urinária (Grauer, 2003). O aumento dos níveis sistêmicos de glicocorticoides (iatrogênico ou por hiperadrenocorticismo) interfere na resistência do hospedeiro e pode causar poliúria. Qualquer afecção que resulte em incapacidade de esvaziar completamente a vesícula urinária (por exemplo, obstrução do fluxo funcional ou anatômica, uma dor que evite o posicionamento para urinar e vários distúrbios da micção) pode permitir a colonização bacteriana e posterior infecção da vesícula urinária. O diabetes mellitus predispõe um animal a ITUI devido à glicosúria, poliúria e redução da imunocompetência (Cowan, 1998, Lulich et al., 2004).

Quadros de cistites são mais frequentemente causados por microrganismos oriundos do trato intestinal do próprio animal, entre elas a bactéria Eschericchia coli. A mesma encontra-se nas fezes, e em situações especiais, essa bactéria migra, infectando a região perineal (Wing, 1999). Após um período de multiplicação, essa bactéria pode invadir a uretra e se localizar na vesícula urinária, causando uma cistite infecciosa (Cowan, 1998). Nelson e Couto, (2001) e Reche Júnior (2005) relatam que a infecção urinária bacteriana em cães corresponde a uma das mais frequentes afecções causadoras de sinais como hematúria, disúria e polaciúria.

A resistência a drogas antibacterianas é um problema cada vez mais importante tanto em humanos quanto em animais. O amplo e, algumas vezes, indiscriminado uso dessas drogas resulta na seleção de bactérias que são inerentemente resistentes (Quinn, 2005). Mecanismos de mutação ou recombinação podem gerar cepas bacterianas resistentes aos antimicrobianos, embora muitas drogas apresentem amplo espectro de ação, e consequentemente falhas terapêuticas podem acontecer (Spinosa, 2002).

Souza Júnior e Fernandez (2004) afirmam que o uso de antimicrobianos de amplo espectro, que são muito utilizados no tratamento de infecções urinárias sem o conhecimento prévio da suscetibilidade, tem aumentado a resistência bacteriana aos antimicrobianos.

Nesse contexto, o presente trabalho tem como objetivo revisar a infecção do trato urinário inferior (ITUI) de cães.

\section{Patógenos na ITUI}

Eschericchia coli, Proteus spp, Pseudomonas aeruginosa e Enterobacter spp são exemplos de patógenos urinários que podem estar associados a linhagens polirresistentes. Portanto, quando antibióticos são selecionados com base em antibiograma, será mais provável que ocorra uma boa resposta clínica (Lulich, 1997).

\section{Resistência Microbiana}

Segundo Wing (1999), contribui para a seleção de linhagens resistentes a adição de antibióticos aos alimentos com fins profiláticos e mais frequentemente, terapêuticos. O mesmo autor relata o surgimento de cepas patogênicas de Eschericchia coli resistentes à tetraciclina como consequência da adição desse antibiótico aos alimentos, bem como também são frequentes estirpes resistentes a outros antibióticos como a estreptomicina, cloronitrina e neomicina, a sulfamidas e, em menor proporção, aos derivados nitrofuramínicos.

Alguns autores relatam que a bactéria com maior frequência de isolamento em casos de cistite infecciosa em cães é a Eschericchia coli, entre eles Blood (1991), Lage (1992), Bartges (2000), Ling, (2004), Lulich et al. (2004), à semelhança do que ocorre em bovinos (Silva, 1990) e em humanos (Herberg \& Schor, 2003). 
Ribeiro, Moreira e Pereira (2008), em estudo que analisou a susceptibilidade a antibióticos de bactérias isoladas de cistite em cães, concluíram que a bactéria com maior frequência foi a E.coli. Quanto ao quesito sensibilidade e resistência microbiana dos isolados analisados, percebeu-se que tais características são bastante variáveis na dependência do agente isolado. Os autores observaram que $100 \%$ dos isolados do gênero Staphylococcus spp foram sensíveis a cefalexina, o mesmo ocorrendo com os antibióticos norfloxacina, cefepima e enrofloxacina, respectivamente para os gêneros Proteus spp, Streptococcus spp, Cytrobacter spp e Klebsiella spp. Por outro lado, a porcentagem máxima de isolados suscetíveis de E.coli foi de $64,7 \%$ para apenas dois antibacterianos, entre eles ciprofloxacina e gentamicina.

Contudo, tais afirmações não correspondem aos relatos de Santos et al. (2005), que identificou como agente etiológico principal da cistite o Staphylococcus aureus, seguido do Streptococcus spp e E.coli em terceiro lugar, ou Azevedo (2003) apud Santos et al. (2005), que identificou o Staphylococcus spp como agente principal, seguido da E.coli.

Souza Júnior e Fernandez (2004) afirmam que é improvável que um único agente quimioterápico possa apresentar todas as qualidades necessárias para ser utilizado no tratamento eficaz de infecções microbianas.

\section{Conclusão}

Destaca-se a necessidade da indicação do isolamento bacteriano, seguido do antibiograma nos casos de cistite bacteriana particularmente recidivantes.

\section{Referências}

BARTGES, J.W. Diseases of the urinary bladder. In: BICHARD, S.J., SHERDING, R.G. (ed) Saunders manual of small animal practice. Philadelphia: W.B. Saunders company, 2000 p.943-957.

BLOOD, D.G. Clínica veterinária. Rio de Janeiro: Guanabara Koogan, 1991. 1263.

COWAN, L.A. Vesicopatias. In: BIRCHARD, S.J., SHERSING, R.G. (ed). Manual Saunders clínica de pequenos animais. São Paulo: Roca, 1998. p.931-942.

GRAUER, G.F. Urinary tract infections. In: NELSON, R.W., COUTO, C.G. (ed). Smal animal internal medicine. Missouri: Mosb, 2003. p.624-630.

HERBERG, I.P., SCHOR, N. Abordagem diagnostica e terapêutica na infecção do trato urinário - ITU. Revista da Associação Médica Brasileira, v. 49, n. 1, p.109-116, 2003.

LAGE, A.L. Diseases of the bladder. In: MORGAN, R.V. (ed). Handbook of small animal practices. Philadelphia: W.B. Saunders company, 1992. p.595-609.

LING, G.V. Infecções bacterianas do trato urinário. In: ETTINGER, S.J., FELDMAN, E.C. (ed). Tratado de medicina interna veterinária. Rio de Janeiro: Guanabara-Koogan, 2004 p.1768-1776.

LULICH, J.P., OSBORNE, C.A. Infecções bacterianas do trato urinário. In: ETTINGER, S.J., FELDMAN, E.C. (ed). Tratado de medicina interna veterinária. São Paulo: Manole, 1997. p. $2453-2470$

LULICH, J.P., OSBORNE, C.A., BARTGES, J.W. Infecções urinárias em caninos. In: ETTINGER, S.J., FELDMAN, E.C. (ed). Tratado de medicina interna veterinária. São Paulo: Manole, 1997. p.2535-2573.

LULICH, J.P., OSBORNE, C.A., BARTGES, J.W., LEHCHAROENSUK, C. Distúrbios do trato urinário inferior dos caninos. In: ETTINGER, S.J., FELDMAN, E.C. (ed). Tratado de medicina interna veterinária. Rio de Janeiro: Guanabara-Koogan, 2004. p.1841-1877.

NELSON, R.W., COUTO, C.G. Medicina interna de pequenos animais. Rio de Janeiro: Guanabara-Koogan, 2001. p.454-455.

QUINN, P.J., MARKEY B.K., CARTER, M.E., DONNELLY, W.J.C., LEONARD, F.C. Microbiologia veterinária e doenças infecciosas. Porto Alegre: Artmed, 2005. 512p.

RECHE JUNIOR, A. The orbifloxacin in the treatment of lower urinary tract infections in cats. Ciência Rural, v 35, n. 6, p.1325-1330, 2005.

RIBEIRO, N. A. S;/ MOREIRA, M. A. B.; PEREIRA, C. A. D. Suscetibilidade a antibióticos de bactérias isoladas de cistite em cães. Revista CFMV, n. 45, p.42-46, 2008.

SANTOS, M.R., AZEVEDO J.S., PETRUCCI, C.G., FISHER, C.D.B., OLIVEIRA, S.J. Suscetibilidade a antimicrobianos, de bactérias isoladas de diversas patologias em cães e gatos, nos anos de 2002 e 2003. Veterinária em Foco, v 2, n. 2, p.157-164, 2005.

SILVA, A.C. Doenças infecciosas em animais domésticos. Recife: Imprensa Universitária da UFRPE, 1990. 157p.

SOUZA JÚNIOR, M.A., FERNANDEZ, L.G. Perfil de susceptibilidade aos antimicrobianos mais comercializados para o tratamento de infecções do trato urinário no ano de 2003 em Salvador - BA. NewsLab, v 67, p.94-106, 2004.

SPINOSA, H.S. Antibióticos, aminoglicosídeos, polimixinas, bacitracina e vancomicina. In SPINOSA, H.S., GÓRNIAC S.L., BERNARDI M.M. (ed). Farmacologia aplicada à medicina veterinária. Rio de Janeiro: Guanabara Koogan, 2002. p.416-419.

WING, W. Infecções por Eschericchia coli. In: BEER, J. (ed). Doenças infecciosas em animais domésticos. São Paulo: Roca, 1999. p.93-111. 